\title{
Synovial Chondromatosis
}

National Cancer Institute

\section{Source}

National Cancer Institute. Synovial Chondromatosis. NCI Thesaurus. Code C34467.

An uncommon, benign cartilaginous neoplasm usually occurring in adults. The nodular tumor arises from the synovial membranes of joints. It is characterized by the presence of chondrocytes, nuclear pleomorphism, and hyaline cartilage differentiation. Clinical presentation may include joint pain, swelling, and limited range of motion. 